\title{
The potential role of gated myocardial perfusion SPECT imaging in patient selection for cardiac resynchronization therapy
}

\author{
Nina Ajmone Marsan, $\mathrm{MD}, \mathrm{PhD},{ }^{\mathrm{a}}$ and Jeroen J. Bax, $\mathrm{MD}, \mathrm{PhD}^{\mathrm{a}}$ \\ a Department of Cardiology, Leiden University Medical Center, Leiden, The Netherlands
}

Received Jul 11, 2014; accepted Jul 11, 2014

doi: 10.1007/s12350-014-9956-7

\section{See related article, pp. 1062-1071}

Cardiac resynchronization therapy (CRT) is currently recommended in patients with wide QRS complex ( $\geq 120 \mathrm{~ms}$ ), heart failure symptoms, and depressed left ventricular (LV) function (ejection fraction $\leq 35 \%$ ) despite optimal medical therapy. ${ }^{1}$ Several randomized clinical trials provided evidence that in these patients CRT can improve symptoms, LV function, heart failure hospitalizations, and overall mortality. ${ }^{2-4}$ However, this beneficial effect is not homogenous among CRT recipients and previous studies have observed that a substantial group of patients who received CRT according to these selection criteria do not respond favorably to $\mathrm{CRT}^{4-7}$ More importantly, there is no consensus on the definition of response to CRT, and both symptomatic improvement (in New York Heart Association functional class) and echocardiographic improvement ( $\mathrm{LV}$ reverse remodeling, decrease in $\mathrm{LV}$ end-systolic volume, and increase in LV ejection fraction) have been used; when comparing these two definitions of CRT response, it appears that symptomatic improvement occurs more often than echocardiographic improvement, ${ }^{8}$ but that up to $30 \%$ of patients may not show significant improvement in symptoms and/or LV performance. $^{4-7}$

The attention has therefore shifted toward understanding how to improve prediction of CRT response and identify the best candidates for this therapy.

Reprint requests: Jeroen J. Bax, MD, PhD, Department of Cardiology, Leiden University Medical Center, Albinusdreef 2, 2333 ZA Leiden, The Netherlands; j.j.bax@lumc.nl

J Nucl Cardiol 2014;21:1072-4.

$1071-3581 / \$ 34.00$

Copyright (c) 2014 American Society of Nuclear Cardiology.
Presence of cardiac dyssynchrony (either atrio-ventricular, inter-ventricular of intra-ventricular) seems to be the logic pre-requisite for a good effect of CRT. Current guidelines indicate that a dyssnchronous contraction might be better reflected by a significantly prolonged QRS interval (>150 ms) and by a typical left-bundle branch block QRS morphology, for which a class IA indication was given. ${ }^{1}$ However, several observational studies have also suggested that the direct assessment of LV mechanical dyssynchrony could improve outcomes in CRT recipients. ${ }^{9-17}$ Different imaging techniques have been proposed for this purpose, including echocardiography, magnetic resonance imaging, computed tomography, and nuclear imaging. ${ }^{9-17}$ Echocardiography is the most widely used technique, providing several imaging tools for LV dyssynchrony assessment, such as tissue Doppler imaging (TDI), speckle tracking twodimensional strain analysis, and three-dimensional echocardiography. ${ }^{9-12}$ TDI was first introduced and widely applied in single-center studies, with promising results for predicting CRT response. However in a multi-center setting, TDI measures of dyssynchrony showed reduced feasibility and reproducibility mainly due to technical issues and differences in vendors. ${ }^{18} \mathrm{It}$ also became evident that pathophysiological issues, such as the presence, extent, and location of scar tissue, are of additional importance. ${ }^{7}$ Particularly, the presence of scar tissue may limit the response to CRT, as demonstrated in several studies using contrast-enhanced magnetic resonance $^{15,19}$; the larger the extent of scar tissue, the lesser the response to CRT. It has also been demonstrated that when the LV lead is positioned in areas of transmural scar tissue or outside LV site of latest mechanical activation, the response to CRT is limited. ${ }^{15,19-22}$

Gated myocardial perfusion single photon emission computed tomography (GMPS) has been also proposed for LV dyssynchrony assessment using phase analysis. This is a count-based method that extracts the phase from the regional LV count changes during the cardiac 
cycle. Phase information is related to the onset of mechanical contraction in the 3D myocardial wall and therefore provides information on the synchrony of LV contraction. This technique has been implemented in various software programs, including the Emory Cardiac Toolbox (ECTb) and the Quantitative Gated SPECT (QGS) from Cedars-Sinai Medical Centre and two main parameters of dyssynchrony can be derived: (1) histogram bandwidth, which includes $95 \%$ of the elements of the phase distribution; and (2) phase standard deviation (SD), which is the standard deviation of the phase distribution. In a normal heart, LV contraction is homogeneous and phase distribution is nearly uniform with a highly peaked distribution. With increasing LV dysssynchrony, histogram bandwidth, and phase SD are expected to increase. Assessment of LV dyssynchrony by these two parameters, being a relatively automated process, is also characterized by a high reproducibility, overcoming the limitation abovementioned for TDI. Previous studies have demonstrated the value of these quantitative indices for predicting CRT response. ${ }^{16,17}$ However, the optimal cut-off values for histogram bandwidth and phase SD to define substantial LV dyssynchrony differed among the ECTb and the QGS software programs, ${ }^{16,17}$ and a head-to-head comparison between software packages was not been performed so far. It was therefore unclear whether this difference related to intrinsic characteristics of the sampling systems of the two software programs or might be related to differences in patient populations.

In the current issue of the Journal, Rastgou et $\mathrm{al}^{18}$ performed a direct comparison of the two quantitative software packages for assessment of LV dyssynchrony parameters in 31 patients with reduced $\mathrm{LV}$ ejection fraction $(21 \% \pm 6 \%)$ and QRS duration of $124 \pm 36 \mathrm{~ms}$. The authors reported a good correlation between the two software programs, both for histogram bandwidth $(r=0.664)$ and phase SD $(r=0.731)$, suggesting that both quantitative packages are providing the same information and can be used to assess LV dyssynchrony. However, the values derived by ECTb were significantly higher than those derived by QGS with a mean difference of 38 for histogram bandwidth and 19.7 for phase SD. These findings suggest that the two software packages cannot be used interchangeably and support the use of different cut-off values for the two software packages to eventually define the range of normal synchrony or significant LV dyssynchrony for both histogram bandwidth and phase SD. This remains to be determined in future studies in patients undergoing CRT, validating cut-off values for LV dyssynchrony by predicting CRT response.
Rastgou et al ${ }^{18}$ also compared the different LV dyssynchrony parameters derived by GMPS with measurements derived from echocardiography using TDI, and only modest correlations were noted. Previous studies comparing LV dyssynchrony assessment by GMPS (using either ECTb or QGS software packages) reported good correlations in patients referred for CRT. ${ }^{16,23}$ The modest correlations between echocardiography and GMPS for assessing LV dyssynchrony may be related to the fact that the population evaluated by Rastgou et al. included a small group of patients with relatively narrow QRS complex $(124.2 \pm 36.3 \mathrm{~ms})$, and therefore with a subset of patients without electrical LV dyssynchrony (QRS duration $<120 \mathrm{~ms}$ ), in whom mechanical dyssynchrony may be minimal or absent.

An important advantage of using GMPS for assessing LV dyssynchrony is that it provides also comprehensive information on LV ejection fraction, LV volumes, myocardial ischemia, scar tissue, and viability. The majority of patients referred for CRT have ischemic heart failure (with underlying cause chronic coronary artery disease), and in these patients GMPS is usually performed during the diagnostic and prognostic workup. In the therapeutic decision-making process, all the abovementioned information can be integrated and can help to decide on therapeutic options: revascularization, medical therapy, or device (CRT or implantable cardioverter defibrillator) therapy.

Future studies could therefore be performed in classical candidates for CRT (wide QRS complex$\geq 120 \mathrm{~ms}$, depressed LV function-ejection fraction $\leq 35 \%$, and heart failure symptoms despite optimal medical therapy) to determine the additional value of GMPS in the selection of patients for CRT. Particularly, information on the presence of LV dyssynchrony and the presence/location of LV scar tissue may further improve prediction of CRT response. In addition, GMPS may prove useful in the guidance of LV lead positioning, specifically to avoid placement of the LV lead in areas of (transmural) scar tissue or outside the site of latest mechanical activation.

\section{Disclosure}

The Department of Cardiology received research grants from Biotronik, Medtronic, Boston Scientific, BMS medical imaging, Edwards Lifesciences, St. Jude Medical \& GE Healthcare.

\section{Conflict of interest}

Authors have no conflict of interest to disclose. 


\section{References}

1. Brignole M, Auricchio A, Baron-Esquivias G, Bordachar P, Boriani $\mathrm{G}$, Breithardt $\mathrm{OA}$, et al. ESC guidelines on cardiac pacing and cardiac resynchronization therapy: The Task Force on cardiac pacing and resynchronization therapy of the European Society of Cardiology (ESC). Developed in collaboration with the European Heart Rhythm Association (EHRA). Eur Heart J 2013;34:2281329.

2. Bristow MR, Saxon LA, Boehmer J, Krueger S, Kass DA, De Marco T, et al. Cardiac-resynchronization therapy with or without an implantable defibrillator in advanced chronic heart failure. $\mathrm{N}$ Engl J Med 2004;350:2140-50.

3. Al-Majed NS, McAlister FA, Bakal JA, Ezekowitz JA. Metaanalysis: Cardiac resynchronization therapy for patients with less symptomatic heart failure. Ann Intern Med 2011;154:401-12.

4. Cleland JG, Daubert JC, Erdmann E, Freemantle N, Gras D, Kappenberger $\mathrm{L}$, et al. The effect of cardiac resynchronization on morbidity and mortality in heart failure. N Engl J Med 2005; 352:1539-49.

5. Abraham WT, Fisher WG, Smith AL, Delurgio DB, Leon AR, Loh E, et al. Multicenter InSync Randomized Clinical Evaluation. Cardiac resynchronization in chronic heart failure. N Engl J Med 2002;346:1845-53.

6. Young JB, Abraham WT, Smith AL, Leon AR, Lieberman R, Wilkoff B, et al. Combined cardiac resynchronization and implantable cardioversion defibrillation in advanced chronic heart failure: The MIRACLE ICD trial. J Am Med Assoc 2003;289:2685-94

7. Bax JJ, Gorcsan J 3rd. Echocardiography and noninvasive imaging in cardiac resynchronization therapy: Results of the PROSPECT (Predictors of Response to Cardiac Resynchronization Therapy) study in perspective. J Am Coll Cardiol 2009;53:1933-43.

8. Yu CM, Bleeker GB, Fung JW, Schalij MJ, Zhang Q, van der Wall $\mathrm{EE}$, et al. Left ventricular reverse remodeling but not clinical improvement predicts long-term survival after cardiac resynchronization therapy. Circulation 2005;112:1580-6.

9. Yu CM, Chau E, Sanderson JE, Fan K, Tang MO, Fung WH, et al. Tissue Doppler echocardiographic evidence of reverse remodeling and improved synchronicity by simultaneously delaying regional contraction after biventricular pacing therapy in heart failure. Circulation 2002;105:438-45.

10. Van Bommel RJ, Bax JJ, Abraham WT, Chung ES, Pires LA, Tavazzi L, et al. Characteristics of heart failure patients associated with good and poor response to cardiac resynchronization therapy: A PROSPECT (Predictors of Response to CRT) sub-analysis. Eur Heart J 2009;30:2470-7.

11. Gorcsan J III, Tanabe M, Bleeker GB, Suffoletto MS, Thomas NC, Saba S, et al. Combined longitudinal and radial dyssynchrony predicts ventricular response after resynchronization therapy. J Am Coll Cardiol 2007;50:1476-83.

12. Kapetanakis S, Bhan A, Murgatroyd F, Kearney MT, Gall N, Zhang Q, et al. Real-time 3D echo in patient selection for cardiac resynchronization therapy. JACC Cardiovasc Imaging 2011;4:1626.

13. Truong QA, Singh JP, Cannon CP, Sarwar A, Nasir K, Auricchio A, et al. Quantitative analysis of intraventricular dyssynchrony using wall thickness by multidetector computed tomography. JACC Cardiovasc Imaging 2008;1:772-81.

14. Chalil S, Stegemann B, Muhyaldeen S, Khadjooi K, Smith RE, et al. Intraventricular dyssynchrony predicts mortality and morbidity after cardiac resynchronization therapy: A study using cardiovascular magnetic resonance tissue synchronization imaging. J Am Coll Cardiol 2007;50:243-52.

15. Marsan NA, Westenberg JJ, Ypenburg C, Van Bommel RJ, Roes $\mathrm{S}$, Delgado V, et al. Magnetic resonance imaging and response to cardiac resynchronization therapy: Relative merits of left ventricular dyssynchrony and scar tissue. Eur Heart J 2009;30:2360-7.

16. Boogers MM, Van Kriekinge SD, Henneman MM, Ypenburg C, Van Bommel RJ, Boersma E, et al. Quantitative gated SPECTderived phase analysis on gated myocardial perfusion SPECT detects left ventricular dyssynchrony and predicts response to cardiac resynchronization therapy. J Nucl Med 2009;50:718-25.

17. Henneman MM, Chen J, Dibbets-Schneider P, Stokkel MP, Bleeker GB, Ypenburg C, et al. dyssynchrony as assessed with phase analysis on gated myocardial perfusion SPECT predict response to CRT? J Nucl Med 2007;48:1104-11.

18. Rastgou F, Shojaeifard M, Amin A, Ghaedian T, Firoozabadi H, Malek $\mathrm{H}$, et al. Assessment of left ventricular mechanical dyssynchrony by phase analysis of gated-SPECT myocardial perfusion imaging and tissue Doppler imaging: Comparison between QGS and ECTb software packages. J Nucl Cardiol 2014. doi:10.1007/s12350-014-9941-1.

19. Chung ES, Leon AR, Tavazzi L, Sun JP, Nihoyannopoulos P, Merlino J, et al. Results of the predictors of response to CRT (PROSPECT) trial. Circulation 2008;117:2608-16.

20. White JA, Yee R, Yuan X, Krahn A, Skanes A, Parker M, et al. Delayed enhancement magnetic resonance imaging predicts response to cardiac resynchronization therapy in patients with intraventricular dyssynchrony. J Am Coll Cardiol 2006;48: 1953-60.

21. Auricchio A, Fantoni C, Regoli F, Carbucicchio C, Goette A, Geller C, et al. Characterization of left ventricular activation in patients with heart failure and left bundle-branch block. Circulation 2004;109:1133-9.

22. Khan FZ, Virdee MS, Palmer CR, Pugh PJ, O'Halloran D, Elsik $\mathrm{M}$, et al. Targeted left ventricular lead placement to guide cardiac resynchronization therapy: The TARGET study: A randomized, controlled trial. J Am Coll Cardiol 2012;59:1509-18.

23. Henneman MM, Chen J, Ypenburg C, Dibbets P, Bleeker GB, Boersma E, et al. Phase analysis of gated myocardial perfusion single-photon emission computed tomography compared with tissue Doppler imaging for the assessment of left ventricular dyssynchrony. J Am Coll Cardiol 2007;49:1708-14. 